\title{
The combinatorial approach of laser- captured microdissection and reverse transcription quantitative polymerase chain reaction accurately determines HER2 status in breast cancer
}

Elisabeth Hofmann ${ }^{1 \dagger}$, Rita Seeboeck ${ }^{1,2+}$, Nico Jacobi ${ }^{1}$, Peter Obrist ${ }^{2}$, Samuel Huter ${ }^{2}$, Christian Klein ${ }^{1}$, Kamil Oender ${ }^{3}$, Christoph Wiesner ${ }^{1}$, Harald Hundsberger ${ }^{1}$ and Andreas Eger ${ }^{1 *}$

\begin{abstract}
Background: HER2 expression in breast cancer correlates with increased metastatic potential, higher tumor recurrence rates and improved response to targeted therapies. Fluorescence in situ hybridization (FISH) and immunohistochemistry $(\mathrm{IHC})$ are two methods commonly used for the analysis of HER2 in the clinic. However, lack of standardization, technical variability in laboratory protocols and subjective interpretation are major problems associated with these testing procedures.

Methods: Here we evaluated the applicability of reverse-transcription quantitative polymerase chain reaction (RT-qPCR) for HER2 testing in breast cancer. We tested thirty formaldehyde-fixed and paraffin-embedded tumor samples by RT-qPCR, FISH and IHC and analysed and compared the data from the three methods.

Results: We found that laser-captured microdissection is essential for the accurate determination of HER2 expression by RT-qPCR. When isolating RNA from total tumor tissue we obtained a significant number of false negative results. However, when using RNA from purified cancer cells the RT-qPCR data were fully consistent with FISH and IHC. In addition we provide evidence that ductal carcinomas might be further classified by the differential expression of HER3 and HER4.
\end{abstract}

Conclusions: Laser-captured microdissection in combination with RT-qPCR is a precise and cost-effective diagnostic approach for HER2 testing in cancer. The PCR assay is simple, accurate and robust and can easily be implemented and standardized in clinical laboratories.

Keywords: Breast cancer, Personalized medicine, HER2, Microdissection, Polymerase chain reaction

\section{Background}

The epidermal growth factor receptor (EGFR) family is involved in the regulation of cell proliferation, differentiation and survival $[1,2]$. The family consists of four genes that have evolved from a single ancestor (HER1 or EGFR; HER2/Neu or ERBB2; HER3 or

\footnotetext{
* Correspondence: andreas.eger@fh-krems.ac.at

${ }^{\dagger}$ Equal contributors

'Department Life Sciences, IMC University of Applied Sciences Krems,

Piaristengasse 1, A-3500 Krems, Austria

Full list of author information is available at the end of the article
}

ERBB3, and HER4 or ERBB4). Functional aberrations of HER family members have been causally linked to the pathogenesis of a variety of human cancers including lung, colon, breast and ovarian carcinomas [3-5].

Approximately twenty percent of all breast cancers exhibit an amplification and overexpression of the HER2 gene [6]. Overexpression of HER2 can confer a selective growth and survival advantage on cancer cells and cause a more aggressive breast cancer phenotype [7]. Elevated expression of HER2 has been 
associated with poor prognosis including increased metastatic burden and higher recurrence and mortality rates, diminished response to anti-hormone and doxorubicin-based chemotherapy and increased sensitivity to anthracycline- and taxane-based chemotherapy [8-13]. Targeted inhibition of HER2 with trastuzumab (Herceptin ${ }^{\mathrm{TM}}$; Genentech), pertuzumab (Perjeta ${ }^{\circ}$ Genentech/Roche) or lapatinib (Tykerb ${ }^{\mathrm{Tn}}$, GlaxoSmithKline) has significantly improved clinical outcome, both in the metastatic and in the adjuvant settings [14-21]. Only patients whose tumors overexpress HER2 benefit from the treatments whereas low HER2 levels indicate non-responsiveness. As a consequence the accurate quantification of HER2 expression in breast cancer is critical for selecting the right therapy and optimizing clinical treatment modalities [22-24].

Elevated HER2 protein levels are tightly associated with gene amplification. As a result HER2 status is commonly analyzed by fluorescence in situ hybridization (FISH) [25-30]. Alternatively HER2 protein levels can be semi-quantitatively assessed by immunohistochemistry (IHC) $[25,31,32]$. The rates of concordance between IHC and FISH range from eighty to ninety percent $[23,33,34]$. FISH has been reported to be more accurate, reproducible and robust than IHC [35]. However both assays are suboptimal and significant variability can arise from the lack of standardization in tissue sampling and handling, antibody diversity, chromosome 17 and CEP17 heterogeneity, instrument calibration and observer subjectivity [23, 36, 37]. Determination of HER2 mRNA levels by real-time polymerase chain reaction (qPCR) has been suggested as simple and cost-effective alternative to FISH and IHC [38]. The procedure can be fully automated, standardized and performed on small samples and biopsies. However to this day comparatively few studies have evaluated the clinical applicability of RT-qPCR for HER2 testing. The available data are conflicting and range from weak to high concordance rates with FISH and IHC [38-44]. One drawback of previous studies was that mRNA has mostly been isolated from whole tumor tissues. Abundance of non-tumorigenic stroma cells might significantly influence the overall sensitivity of the assay and yield false negative results $[41,45]$. Here we assessed the HER2 status in thirty ductal carcinomas of the breast by FISH, IHC and RT-qPCR. We could demonstrate a high concordance between the three approaches when using microdissected, formaldehyde-fixed and paraffin-embedded (FFPE) tissue for RNA isolation. Moreover we could detect highly variable expression of HER3 and HER4 suggesting that both could be used as additional markers for refining predictions on prognosis and treatment response.

\section{Methods}

\section{Formaline-fixed and paraffin-embedded (FFPE) tissue samples and laser-captured microdissection}

Standard FFPE sectioning was performed with the Leica microtome RM 2255. For laser-captured microdissection $5 \mu \mathrm{m}$ FFPE sections were prepared and mounted onto Leica FrameSlides (PET-Membrane 1.4 $\mu$ m, Leica). The dried slides were subjected to a quick protocol of haematoxylin/eosin staining: the samples were incubated in xylene for $5 \mathrm{~s}$, in $96 \%$ ethanol for $30 \mathrm{~s}$, in $70 \%$ ethanol for $20 \mathrm{~s}$, in $\mathrm{ddH}_{2} \mathrm{O}$ for $20 \mathrm{~s}$, in haematoxylin for $55 \mathrm{~s}$, in $\mathrm{ddH}_{2} \mathrm{O}$ for $30 \mathrm{~s}$, in HCl-ethanol for $15 \mathrm{~s}$, in $\mathrm{ddH}_{2} \mathrm{O}$ for $20 \mathrm{~s}$, in $80 \%$ ethanol for $30 \mathrm{~s}$, in eosin for $20 \mathrm{~s}$, in $96 \%$ ethanol for $25 \mathrm{~s}$, in $100 \%$ ethanol for $25 \mathrm{~s}$ and finally in xylene for $30 \mathrm{~s}$. Tumour regions $(\sim 10000$ cells) were selected and laser cut (CryLaS FTSS 355-50, Leica) under a Leica DM6000B microscope. The study was performed according to international and regional ethical guidelines and was approved by the ethics commission of Lower Austria and the Danube University Krems, Austria (No. EK GZ 01/2015-2018).

\section{Immunohistochemistry (IHC)}

For the immunohistochemical HER2 staining, FFPE tissue sections were prepared and stained using the Dako Autostainer Universal Staining System (Dako). $2.5 \mu \mathrm{m}$ thick sections of the FFPE samples were prepared and mounted onto silated microscopy slides (HistoSil slides, Stölzle-Oberglas). The dried slides were deparaffinated and rehydrated by immersion in xylene followed by immersion in ethanol of decreasing concentration (96\%, $80 \%, 70 \%$ ). Epitope demasking was performed in a boiling citrate buffer $\mathrm{pH} 6$ (Dako REAL ${ }^{\mathrm{TM}}$ Target Retrieval Solution, Dako). Staining for HER2 was performed using a rabbit polyclonal antibody directed against ERBB2/ HER2 (Dako, A0485) diluted 1:500 in the EnVision ${ }^{\text {TM }}$ FLEX Antibody Diluent (Dako). As a secondary antibody a horseradish peroxidase coupled polymer (EnVision+, Dako) was applied, which reacts with the substrate chromogen 3,3'-diaminobenzidinetetrahydrochloride (Liquid DAB+, Dako). Counterstaining for nuclei was performed using haematoxylin (Dako).

\section{Fluorescent in situ hybridization (FISH)}

FISH was performed on $4 \mu \mathrm{m}$ thick FFPE sections immobilized on silated glass microscopy slides (HistoSil slides, Stölzle-Oberglas). Staining was perfomed using the Vysis TOP2A/HER2/CEP 17 FISH Probe Kit (Abbott) following the manufacturer's instructions. The pretreatment conditions were slightly changed, using a citrate buffer pH 6 (Gatt-Koller) for $70 \mathrm{~min}$ at $80^{\circ} \mathrm{C}$ instead of a Na-SCN solution. Fluorescent signals were analysed under a Leica DM6000B microscope. FISH data 
were evaluated according to the ASCO/CAP guidelines (http://www.asco.org/).

\section{RNA extraction and reverse transcription (RT)}

Total RNA was extracted from total tumor tissue sections or from microdissected (laser-captured) samples yielding only cancer cells. The RNeasy FFPE kit including an on-column DNase I digestion (Qiagen; version 09/2011) was used for RNA extraction according to the manufacturer's instructions. For deparaffinization the FFPE tissue sections were treated with xylene.

Reverse transcription was performed using total RNA according to the combined random hexamer and oligo(dT) priming protocol of the Transcriptor First Strand cDNA Synthesis Kit (Roche) in a final volume of $20 \mu \mathrm{l}$. Control reactions containing RNA but no reverse transcriptase were tested negative for genomic DNA contamination by qPCR.

\section{Real-time quantitative PCR (qPCR)}

Gene expression was assessed by RT-qPCR with eukaryotic translation elongation factor 1 alpha 1 (EEF1A1) as endogenous control gene. For target gene quantification pre-designed TaqMan ${ }^{\circ}$ Gene Expression Assays (EGFR: Hs01076093_g1, HER2: Hs01001580_m1, HER3: Hs00176538_m1 and HER4: Hs00955525_m1; Life Technologies) were used. Whereas the target gene probes were labeled with 6-carboxyfluorescein (FAM), the EEF1A1 probe was labeled with Cy5 at the $5^{\prime}$-end and with a black-hole quencher (BHQ2) at the 3 '-end (MWG Eurofins) in order to allow simultaneous quantification of EEF1A1 and HER2 in one reaction (duplex reaction). The duplex qPCR reaction mix contained a final volume of $15 \mu \mathrm{l} \mathrm{Taqman}{ }^{\circ}$ Gene Expression Mastermix (Life Technologies), HER2 Taqman ${ }^{\circ}$ Gene Expression Assay, $600 \mathrm{nM}$ EEF1A1 primers (MWG Eurofins), $200 \mathrm{nM}$ EEF1A1 probe and $1 \mu \mathrm{l}$ of cDNA. For HER1, HER3 and HER4 singleplex reactions were performed containing Taqman ${ }^{\circ}$ Gene Expression Mastermix (Life Technologies), Taqman ${ }^{\circ}$ Gene Expression Assay, and $1 \mu \mathrm{l}$ of cDNA. Samples were measured in triplicates. All reactions were pipetted in rotor discs-100 using the Qiagility automated pipetting system (Qiagen). All qPCRs were run on a Rotor-Gene Q (Qiagen) using the following cycling conditions: $10 \mathrm{~min}$ at $95{ }^{\circ} \mathrm{C}$ for initial denaturation followed by 45 cycles of $95{ }^{\circ} \mathrm{C}$ for $20 \mathrm{~s}$ and $60{ }^{\circ} \mathrm{C}$ for $1 \mathrm{~min}$. Data were analysed using the RotorGene Q Series Software (Qiagen) and relative target gene expression levels were calculated according to the comparative Cq method [46]. Gene expression levels of the target genes were calculated relative to the endogenous control gene and depicted as relative expression levels in arbitrary units (AU).

\section{Statistical analysis of RT-qPCR data}

For the classification of tumors with respect to HER2-, HER3- and HER4 mRNA levels we determined cut-off values using the algorithm developed by Budczies et al., at the Charité Universitätsmedizin Berlin [47]. The statistical relevance of the difference between HER2 positive and HER2 negative samples and correlations among HER2, HER3 and HER4 expression was analysed with the Mann-Whitney test (two-tailed) using GraphPad Prism (version 6.03 for Windows, Graphpad Software, www.graphpad.com).

\section{Results}

The HER2 status in breast cancer is commonly tested by IHC and FISH. Both methods have been approved by the US Food and Drug Administration for HER2 testing in clinical laboratories [23]. The applicability of RTqPCR for HER2 assessment has not been fully established yet. In the present study we directly compared the performance of IHC, FISH and RT-qPCR using thirty formaldehyde-fixed and paraffin-embedded (FFPE) ductal carcinoma samples selected from the archive. According to FISH and IHC twenty samples tested negative and ten positive for HER2 (Table 1). Grading of IHC assays was based on a $0,1+, 2+$ and $3+$ scoring system [20]. FISH was scored positive when the HER2/CEP17 ratio exceeded $2.2[17,21]$. Representative images of each group are shown in Fig. 1.

For RT-qPCR the RNA was isolated from two different sources. First RNA was harvested from whole FFPE tumor tissue. Second RNA was isolated exclusively from cancer cells after separating cancer cells from the tumor stroma by laser-captured microdissection. Both RNA fractions were subsequently processed for HER2 specific RT-qPCR. HER2 mRNA levels were normalized to the expression of the endogenous control gene EEF1A1 using the comparative $\mathrm{Cq}$ method [46]. Independent classification into HER2 positive and negative tumors was performed using the publicly available cut-off finder algorithm [47] (http://molpath.charite.de/cutoff). When RNA was isolated from total tumor tissue we could detect seven tumors with elevated HER2 mRNA levels (Fig. 2a). On the other hand when using lasercaptured microdissection we could identify ten tumors with significantly increased HER2 mRNA expression (Fig. 2b).

In order to investigate the relationship among DNA amplification, mRNA and protein levels we compared the HER2 data obtained by FISH, IHC and RT-qPCR. In total tumor tissue we detected a significant discordance between RT-qPCR and the standard methods. Of the ten HER2 positive tumors identified by FISH and IHC only seven scored positive in the RT-qPCR approach when using RNA from total tumor tissue (Fig. 3a). On the 
Table 1 Archive samples of ductal, invasive mammary carcinoma

\begin{tabular}{|c|c|c|c|c|c|c|c|c|c|c|}
\hline Sample & Age & Grade & Stage & LN & HER2 IHC & HER2 FISH & HER2 qPCR* & HER3 qPCR* & HER4 qPCR* & EGFR qPCR* \\
\hline 01 & 58 & 2 & pT1b & NO & 0 & 1,0 & 121 & 46 & - & 5,9 \\
\hline 02 & 60 & 3 & ypT1c & yN1a & 0 & 1,1 & 580 & - & - & - \\
\hline 03 & 75 & 2 & pT1b & NO & 0 & 1,1 & 518 & 1133 & 215 & - \\
\hline 04 & 59 & 2 & pT1b & No & 1 & 0,9 & 474 & 540 & 439 & - \\
\hline 05 & 59 & 2 & pTa & - & 2 & 1,2 & 632 & - & - & - \\
\hline 06 & 70 & 3 & pT1c & NO & 1 & 0,9 & 1198 & - & - & - \\
\hline 07 & 53 & 2 & pT1b & SNOi- & 1 & 0,9 & 474 & 680 & 66 & - \\
\hline 08 & 68 & 2 & pT1c & $\mathrm{N} 2 \mathrm{a}$ & 1 & 0,9 & 603 & 1812 & 281 & - \\
\hline 09 & 41 & 2 & pT1c & $\mathrm{N} 1$ & 1 & 1,0 & 305 & 341 & 133 & - \\
\hline 10 & 74 & 2 & pT1b & $N X$ & 1 & 1,0 & 473 & 1020 & - & - \\
\hline 11 & 68 & 2 & pT1b & NO & 1 & 1,0 & 358 & 196 & 107 & - \\
\hline 12 & 52 & 2 & pT2 & NO & 1 & 1,0 & 598 & 1149 & - & - \\
\hline 13 & 79 & 2 & pT2 & $\mathrm{N} 1$ & 1 & 1,0 & 186 & 204 & 145 & - \\
\hline 14 & 50 & 2 & pT1c & NO & 1 & 1,0 & 796 & - & - & - \\
\hline 15 & 53 & 2 & pT2 & - & 1 & 1,0 & 194 & 687 & 379 & - \\
\hline 16 & 76 & 2 & pT2 & $\mathrm{N} 2 \mathrm{a}$ & 1 & 1,0 & 530 & 440 & 1167 & - \\
\hline 17 & 67 & 2 & pT1b & N1a & 1 & 1,0 & 172 & 186 & 93 & - \\
\hline 18 & 81 & 2 & pT2 & NO & 1 & 1,0 & 141 & 84 & - & - \\
\hline 19 & 73 & 2 & pT1c & NO & 1 & 1,0 & 935 & - & - & - \\
\hline 20 & 48 & 2 & урт2 & yNO & 1 & 1,0 & 294 & - & - & 6,4 \\
\hline 21 & 74 & CIN & pT1mic & - & 3 & 2,9 & 15109 & 4350 & - & - \\
\hline 22 & 26 & 3 & pT2 & NO & 3 & 3,1 & 6241 & 149 & 59 & 0,6 \\
\hline 23 & 34 & 3 & pT2 & N3a & 3 & 4,1 & 7865 & 125 & 78 & - \\
\hline 24 & 67 & 2 & pT1c & $\mathrm{N} 1 \mathrm{~b}$ & 3 & 4,3 & 44849 & 406 & 120 & - \\
\hline 25 & 65 & 2 & урT2 & $\mathrm{N} 2 \mathrm{a}$ & 3 & 5,3 & 12160 & 1053 & - & - \\
\hline 26 & 59 & 2 & pT1c & No & 3 & 5,4 & 10934 & 159 & - & - \\
\hline 27 & 66 & 3 & pT2 & N1a & 3 & 6,0 & 11866 & 175 & - & - \\
\hline 28 & 49 & $\mathrm{DCl} \| \mathrm{I}$ & pT1mic & - & 3 & 2,3 & 12609 & - & - & - \\
\hline 29 & 82 & 2 & pT3 & $N X$ & 3 & 2,4 & 4541 & 6157 & - & - \\
\hline 30 & 68 & 2 & pT4d & $\mathrm{N} 2 \mathrm{a}$ & $3+$ & 2,8 & 4019 & 5554 & 720 & - \\
\hline
\end{tabular}

LN lymph node pathology

*relative expression of HER-family members in arbitrary units (RT-qPCR using RNA from laser-captured microdissection)

-: below the detection limit

other hand when RNA was isolated exclusively from cancer cells the RT-qPCR data were fully consistent with FISH and IHC (Fig. 3b). Even though the sample size is rather small one can conclude that RT-qPCR results in high false-negative rates when RNA is extracted from total tumor tissue (three out of ten). Hence lasercaptured microdissection prior to RT-qPCR strongly improved the accuracy of HER2 mRNA quantification in the tumor.

HER1, HER2 and HER3 were all implicated in the development and progression of cancer $[4,48]$. To quantitatively assess the expression of HER1, HER3 and HER4 in the breast cancer samples we performed RT-qPCR using RNA derived from microdissected FFPE tissues. Significant but very low expression of HER1 (EGFR) was detected only in ten percent of the tumors (Table 1). HER4 expression could be found in around fifty percent of the breast cancer samples (Table 1 and Fig. 4a). The tumors could be separated into two groups expressing either low or high HER4 mRNA levels (Fig. 4a). However, the amount of HER4 mRNA varied stochastically in the HER2-negative and HER2-positive tumors (Table 1 and Fig. 4a ). HER3 was expressed in the majority of the breast cancer samples. Ninety percent of the HER2-positive and around seventy percent of the HER2-negative cells expressed HER3 mRNA (Table 1). Analogous to HER4 


\section{a IHC}
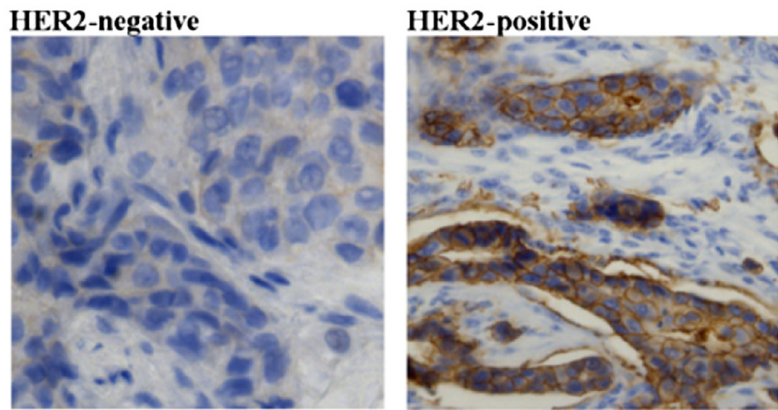

\section{b FISH}
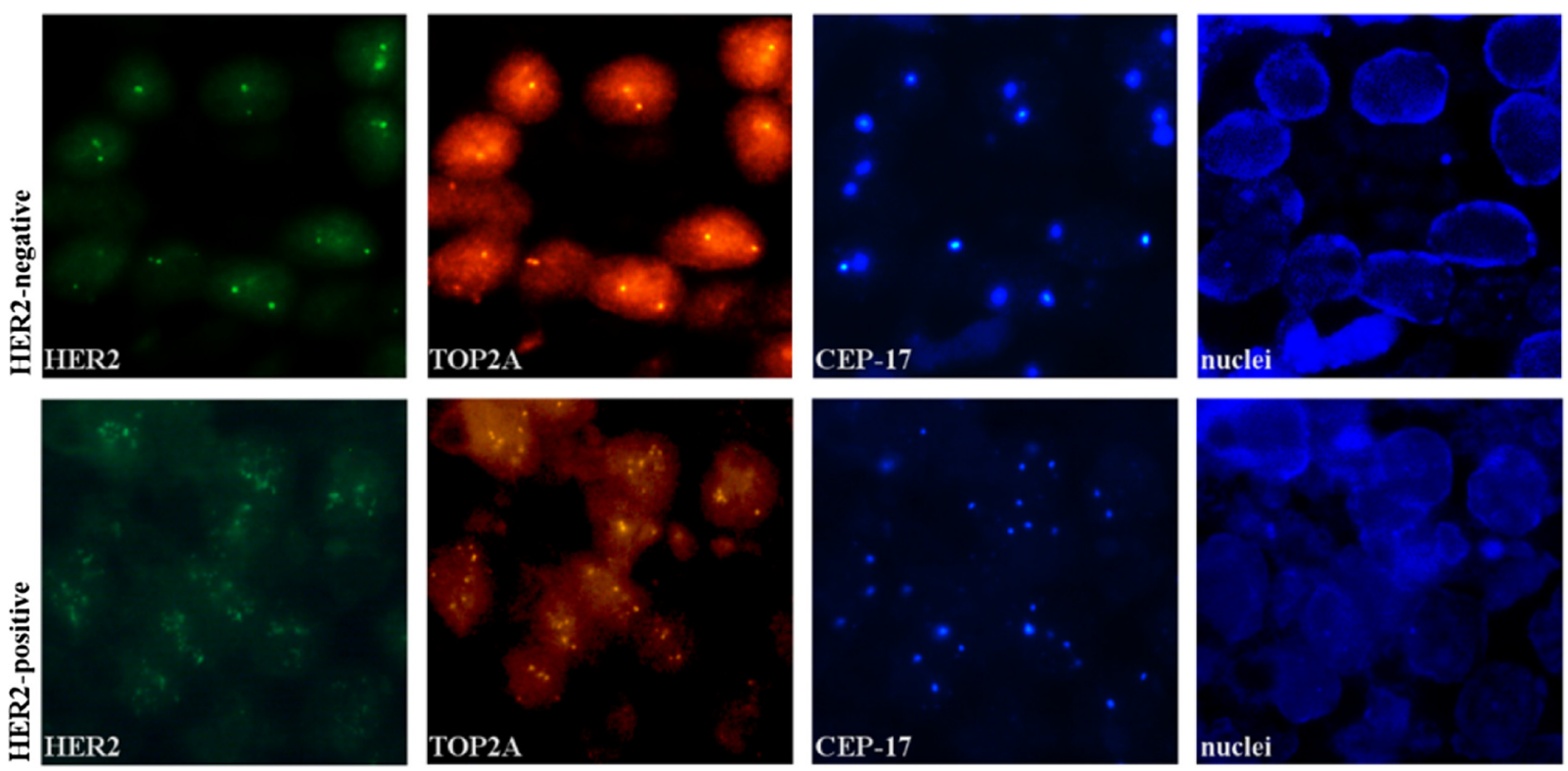

Fig. 1 Representative images of HER2-negative and HER2-positive breast cancer specimen. a Tumor sections were subjected to IHC using HER2 specific antibodies and were counterstained for nuclei using haematoxylin (blue). Brown colour indicates subcellular localization of HER2. b Determination of HER2 amplification by FISH. Specific probes for HER2 (green) TOP2A (orange) and CEP-17 (blue) were used. The nuclei were selectively stained with DAPI

we could separate the tumors into either low or high HER3 expressing subpopulations (Fig. 4b). Interestingly all HER2 negative cancer cells showed also low HER3 expression. On the other hand in the HER2- positive samples we could detect a significant fraction of tumors that additionally expressed very high levels of HER3 mRNA (Fig. 4b and Table 1).

\section{Discussion}

Personalized oncology is expected to significantly improve patient care and disease outcome in the near future [49]. Precision therapy requires biomarkers to select the right patients for the right treatment [50, 51]. Technological advances in genomics, proteomics and systems biology have identified a large number of biomarkers with potential clinical value [52-54]. This wealth of information needs to be translated to the clinic. Translation and clinical validation requires experimental tools that allow the accurate and simultaneous analysis of a large number of biomarkers. Genetic testing is superior to immunological and protein- or cell-based technologies [53, 55-57]. Nucleic acids are easily accessible and can be isolated in sufficient quantity and quality from small amounts of archived FFPE samples or biopsies. qPCR is presently the gold standard method for assessing genetic biomarkers. Precise mutational analysis or quantification of gene expression can be performed in a standardized and automated manner. As a consequence the clinical validation of RT-qPCR methods for biomarker assessment is of prime importance in personalized oncology. 


\section{a Relative HER2 mRNA levels in total FFPE tissue}

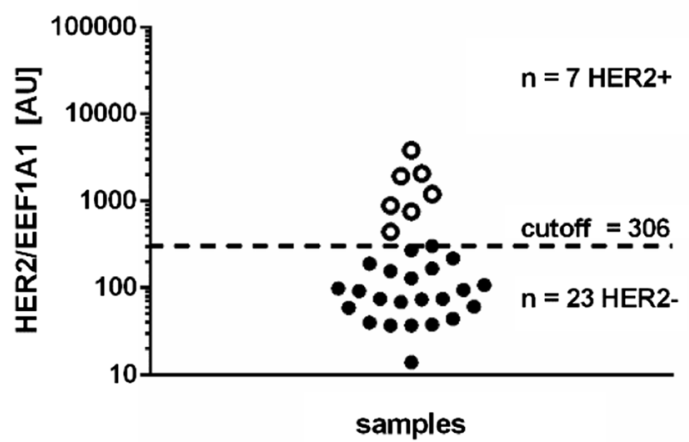

b Relative HER2 mRNA levels in microdissected FFPE tissue

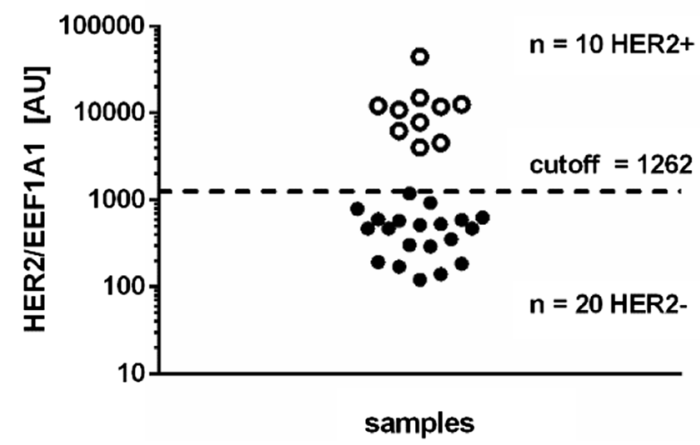

Fig. 2 HER2 mRNA levels in breast cancer specimen. Expression levels of HER2 relative to the endogenous control gene EEF1A1 in arbitrary units (AU) (a) Total FFPE tissue (b) microdissected FFPE tissue. HER2- negative and positive samples were identified using the publicly available cutoff finder algorithm [47]

The HER2 biomarker is instrumental for selecting breast cancer patients that respond to the targeted HER2 inhibitors trastuzumab, pertuzumab and lapatinib $[22,51]$. Despite the clinical importance of HER2 the present diagnostic methods for its detection in the tumor are only semi-quantitative, difficult to standardize and prone to subjective interpretation [23]. Here we analysed the applicability of RT-qPCR for the accurate quantification of HER2 expression in breast cancer. When isolating the RNA from total tumor tissue we found that RT-qPCR gives rather high false-negative results. In line with these findings concerns have also been raised by other groups regarding the sensitivity and accuracy of the qPCR approach [41, 45]. However, when combining RT-qPCR with laser-captured microdissection we could demonstrate that RT-qPCR is fully consistent with FISH and IHC. The focused isolation of RNA from cancer cells significantly improved the sensitivity and accuracy of the qPCR approach.

Signaling by HER family members is a complex and highly integrated network with crosstalk, redundancy and feedback controls and interactions with different effector molecules [4]. Overexpression of different members and complex homo- and heterodimerization is likely to influence the clinical efficacy of targeted HER inhibitors. Here we additionally examined the expression of HER1 (EGFR), HER3 and HER4 in the breast cancer samples by RT-qPCR.

HER1 mRNA levels were extremely low and expression was found in a small fraction of the samples. This is consistent with previous IHC studies that demonstrated HER1 overexpression in only a subset of ductal breast

\section{a Relative HER2 mRNA levels in total FFPE tissue}

\section{b Relative HER2 mRNA levels in microdissected FFPE tissue}
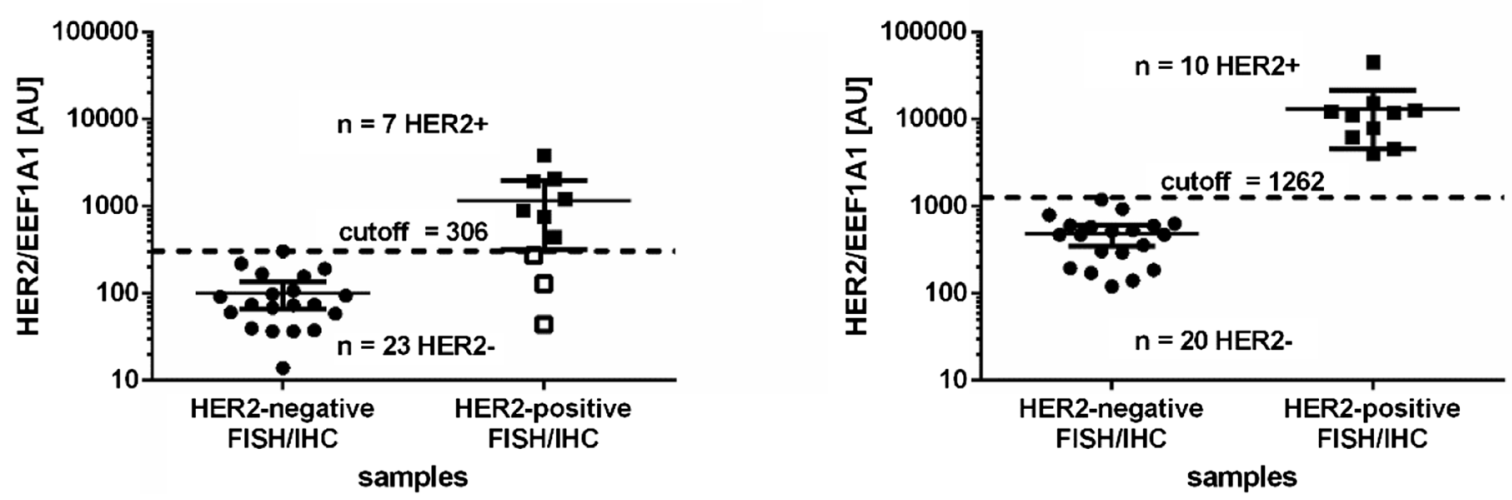

Fig. 3 Assessment of HER2 status using RT-qPCR, FISH and IHC. Relative expression levels of HER2/EEF1A1 in arbitrary units (AU) were calculated for (a) total tumor tissue and (b) microdissected tumor tissue and compared to the HER2 status as determined by IHC and FISH. Mean values and the $95 \%$ confidence interval for the mean is separately indicated for HER2- positive and negative samples. Significantly higher HER2 mRNA levels were detected in IHC/FISH HER2-positive samples with $p<0.001$ and $p<0.0001$ for total FFPE tissue and microdissected FFPE tissue, respectively 
a Relative HER4 mRNA levels in microdissected FFPE tissue

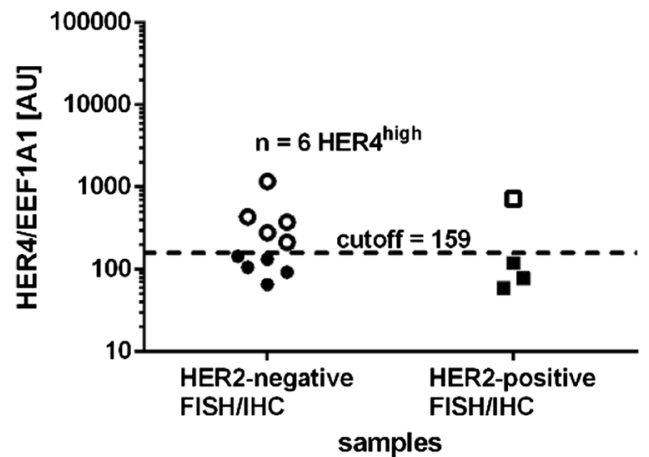

b Relative HER3 mRNA levels in microdissected FFPE tissue

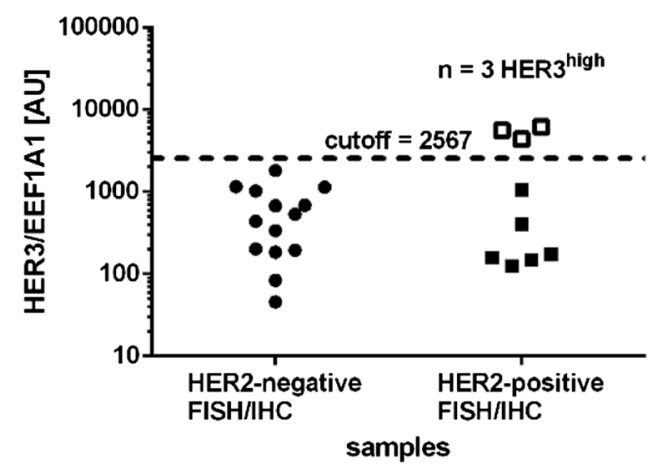

Fig. 4 Relative HER4 and HER3 mRNA levels in breast cancer specimen. a HER3- and (b) HER4-high (open circles) and -low (filled circles) expressing tumors were identified using the cutoff algorithm [47]. The differences between high and low HER3 and HER4 expression are significant with $p<0.01$ for HER3 and $p<0.001$ for HER4

carcinomas [58]. HER4 was expressed in approximately fifty percent of the tumors, and expression levels varied irrespective of whether HER2 was present or not. Previous data on HER4 in breast carcinoma are conflicting. There is evidence that the receptor is a negative regulator of cell proliferation [4]. In some studies HER4 expression has been directly correlated to improved overall survival and diminished tumor grade, metastasis and disease recurrence [4]. Here we could not detect any significant correlation between HER4 expression and tumor differentiation, size or metastatic potential.

HER3 is the preferred hetero-dimerization partner of HER2 in different cancer types [48]. The HER2-HER3 heterodimer was found to be critically involved in tumor initiation and progression and is considered the most active signalling dimer of the HER family in cancer [48, 59, 60]. In our study we could identify two distinct tumor populations that expressed either high or low levels of HER3. Interestingly the highest expression of HER3 was detected in the HER2 positive samples. Overexpression of both HER2 and HER3 might critically influence oncogenic signalling, oncogene addiction and responsiveness to drugs targeting HER and HER-related RTKs. Presently we are planning a large-scale retrospective study for assessing the clinical usability of HER biomarker profiles for predicting therapy response and patient outcome in ductal carcinomas of the breast and in non-small cell lung cancer.

In the future advances in high-throughput PCR and massive parallel sequencing will allow the cost-effective analyses of genetic alterations in cancer cells on a larger scale [61, 62]. Massive parallel sequencing can provide both, information on mutations and genetic rearrangements as well as gene expression (mRNA) levels [63, 64]. These technologies will facilitate the analysis of the genetic make-up of a large panel of genes at a time and thus will have a strong impact on clinical decision making, including the determination of familial predispositions, cancer subclasses, cancer progression, prognosis, therapy selection and tumor recurrence [61]. For the genetic analyses only few cancer cells are necessary making it also an ideal tool for the molecular characterization of circulating cancer cells in the peripheral blood. Massive parallel sequencing will be possible without amplification of the DNA or RNA in the near future $[65,66]$. Thus the cost-effective and routine analyses of large gene panels or whole genomes and transcriptomes will be feasible in the clinic on a daily basis. However, when using mRNA levels as indicators for protein expression pilot studies are necessary for each signaling molecule in order to demonstrate a clear correlation between RNA and protein amounts in different cancer types. Here we could demonstrate that the expression of HER2 mRNA and protein levels were only matching when mRNA was isolated specifically from cancer cells after laser-captured microdissection of ductal carcinomas of the breast. Laser-captured microdissection can easily be standardized and implemented into daily clinical practice and yields mRNA of sufficient quality for qPCR or quantitative sequencing [67]. In addition it offers the advantage for analyzing subpopulations of cancer cells in the tumor to determine tumor heterogeneity and cancer stem cell properties. Both might be critical determinants for therapy selection, treatment success and tumor recurrence.

\section{Conclusion}

Considering the present data we suggest that lasercaptured microdissection in combination with RT-qPCR is an accurate diagnostic approach for HER2 testing in cancer. In contrast to FISH and IHC the qPCR-based assays are simple, accurate and robust, easily standardized 
and automatized and display high sensitivity, specificity and reproducibility. However, additional and larger clinical studies are needed to fully validate the value of RTqPCR for the assessment of HER family members in cancer.

The clinical validation of genetic biomarkers is of prime importance in oncology. Large numbers of validated genetic markers could be simultaneously tested in large-scale studies using high-throughput qPCR or massive parallel sequencing technologies. Comprehensive and multi-parametric genetic profiling of tumors will further advance personalized medicine, improve the efficacy of targeted therapeutics and decrease morbidity and mortality rates in cancer.

\section{Competing interests}

None of the authors have any competing interests in the manuscript

\section{Authors' contributions}

EH: first author, laser-captured microdissection, RT-qPCR, FISH and IHC, data analysis and interpretation, preparation of manuscript, design of figures. RS: first author, laser-captured microdissection, RT-qPCR, FISH and IHC, data analysis and interpretation, preparation of manuscript, design of figures. NJ: co-author, establishment of protocols for laser-captured microdissection, optimization of RT-qPCR. PO: co-author, selection of samples, pathological assessment, study design. SH: laser-captured microdissection. CK: co-author, statistical analysis. KO: CO-author, FISH. CW: co-author, IHC. HH: co-author, IHC. AE: corresponding author, acquisition of funding, conception, design and supervision of the work, establishment of experimental methods, analysis and interpretation of data, literature and data mining, design and lay-out of figures, preparation and writing of manuscript. All authors read and approved the final manuscript.

\section{Acknowledgements}

This work was supported with funds received from the Lower Austria Research and Education Fund (NÖ Forschungs- und Bildungsges.m.b.H., NFB), project number LS09-023 and LS11-013.

\section{Author details}

'Department Life Sciences, IMC University of Applied Sciences Krems, Piaristengasse 1, A-3500 Krems, Austria. ${ }^{2}$ Pathology Laboratory Obrist and Brunhuber, Klostergasse 1, A-6511 Zams, Austria. ${ }^{3}$ Research Program for Rational Drug Design in Dermatology and Rheumatology, Department of Dermatology, Paracelsus Medical University of Salzburg, Müllner Hauptstraße 48, A-5020 Salzburg, Austria.

\section{Received: 4 February 2016 Accepted: 1 April 2016}

Published online: 07 April 2016

\section{References}

1. Avraham $R$, Yarden Y. Feedback regulation of EGFR signalling: decision making by early and delayed loops. Nat Rev Mol Cell Biol. 2011;12(2):104-17.

2. Yarden $Y$, Pines $G$. The ERBB network: at last, cancer therapy meets systems biology. Nat Rev Cancer. 2012;12(8):553-63.

3. Hynes NE, Lane HA. ERBB receptors and cancer: the complexity of targeted inhibitors. Nat Rev Cancer. 2005;5(5):341-54.

4. Roskoski Jr R. The ErbB/HER family of protein-tyrosine kinases and cancer. Pharm Res. 2014;79:34-74.

5. Tebbutt N, Pedersen MW, Johns TG. Targeting the ERBB family in cancer: couples therapy. Nat Rev Cancer. 2013;13(9):663-73.

6. Ross JS, Slodkowska EA, Symmans WF, Pusztai L, Ravdin PM, Hortobagyi GN. The HER-2 receptor and breast cancer: ten years of targeted anti-HER-2 therapy and personalized medicine. Oncologist. 2009;14(4):320-68.

7. Neve RM, Lane HA, Hynes NE. The role of overexpressed HER2 in transformation. Ann Oncol. 2001;12 Suppl 1:S9-13.

8. Gabos Z, Sinha R, Hanson J, Chauhan N, Hugh J, Mackey JR, Abdulkarim B. Prognostic significance of human epidermal growth factor receptor positivity for the development of brain metastasis after newly diagnosed breast cancer. J Clin Oncol Off J Am Soc Clin Oncol. 2006;24(36):5658-63.

9. Paik S, Bryant J, Park C, Fisher B, Tan-Chiu E, Hyams D, Fisher ER, Lippman $\mathrm{ME}$, Wickerham DL, Wolmark N. erbB-2 and response to doxorubicin in patients with axillary lymph node-positive, hormone receptor-negative breast cancer. J Natl Cancer Inst. 1998;90(18):1361-70.

10. Paik S, Bryant J, Tan-Chiu E, Yothers G, Park C, Wickerham DL, Wolmark N. HER2 and choice of adjuvant chemotherapy for invasive breast cancer: National Surgical Adjuvant Breast and Bowel Project Protocol B-15. J Natl Cancer Inst. 2000;92(24):1991-8.

11. Pritchard Kl, Messersmith H, Elavathil L, Trudeau M, O'Malley F, Dhesy-Thind B. HER-2 and topoisomerase II as predictors of response to chemotherapy. J Clin Oncol. 2008;26(5):736-44.

12. Seshadri R, Firgaira FA, Horsfall DJ, McCaul K, Setlur V, Kitchen P. Clinical significance of HER-2/neu oncogene amplification in primary breast cancer. The South Australian Breast Cancer Study Group. J Clin Oncol. 1993;11(10):1936-42.

13. Slamon DJ, Clark GM, Wong SG, Levin WJ, Ullrich A, McGuire WL. Human breast cancer: correlation of relapse and survival with amplification of the HER-2/neu oncogene. Science. 1987;235(4785):177-82.

14. Baselga J, Cortes J, Kim SB, Im SA, Hegg R, Im YH, Roman L, Pedrini JL Pienkowski T, Knott A. Pertuzumab plus trastuzumab plus docetaxel for metastatic breast cancer. N Engl J Med. 2012;366(2):109-19.

15. Cobleigh MA, Vogel CL, Tripathy D, Robert NJ, Scholl S, Fehrenbacher L, Wolter JM, Paton V, Shak S, Lieberman G. Multinational study of the efficacy and safety of humanized anti-HER2 monoclonal antibody in women who have HER2-overexpressing metastatic breast cancer that has progressed after chemotherapy for metastatic disease. J Clin Oncol. 1999;17(9):2639-48.

16. Geyer CE, Forster J, Lindquist D, Chan S, Romieu CG, Pienkowski T, JagielloGruszfeld A, Crown J, Chan A, Kaufman B. Lapatinib plus capecitabine for HER2-positive advanced breast cancer. N Engl J Med. 2006;355(26):2733-43.

17. Piccart-Gebhart MJ, Procter M, Leyland-Jones B, Goldhirsch A, Untch M, Smith I, Gianni L, Baselga J, Bell R, Jackisch C. Trastuzumab after adjuvant chemotherapy in HER2-positive breast cancer. N Engl J Med. 2005;353(16): 1659-72.

18. Romond EH, Perez EA, Bryant J, Suman VJ, Geyer Jr CE, Davidson NE, TanChiu E, Martino S, Paik S, Kaufman PA. Trastuzumab plus adjuvant chemotherapy for operable HER2-positive breast cancer. N Engl J Med. 2005;353(16):1673-84.

19. Sjogren S, Inganas M, Lindgren A, Holmberg L, Bergh J. Prognostic and predictive value of c-erbB-2 overexpression in primary breast cancer, alone and in combination with other prognostic markers. J Clin Oncol. 1998;16(2):462-9.

20. Slamon D, Eiermann W, Robert N, Pienkowski T, Martin M, Press M, Mackey J, Glaspy J, Chan A, Pawlicki M. Adjuvant trastuzumab in HER2-positive breast cancer. N Engl J Med. 2011;365(14):1273-83.

21. Slamon DJ, Leyland-Jones B, Shak S, Fuchs H, Paton V, Bajamonde A, Fleming T, Eiermann W, Wolter J, Pegram M. Use of chemotherapy plus a monoclonal antibody against HER2 for metastatic breast cancer that overexpresses HER2. N Engl J Med. 2001;344(11):783-92.

22. Montemurro F, Scaltriti M. Biomarkers of drugs targeting HER-family signalling in cancer. J Pathol. 2014;232(2):219-29.

23. Perez EA, Cortes J, Gonzalez-Angulo AM, Bartlett JM. HER2 testing: current status and future directions. Cancer Treat Rev. 2014;40(2):276-84.

24. van de Vijver MJ. Molecular tests as prognostic factors in breast cancer. Virchows Archiv. 2014;464(3):283-91.

25. Bofin AM, Ytterhus B, Martin C, O'Leary JJ, Hagmar BM. Detection and quantitation of HER-2 gene amplification and protein expression in breast carcinoma. Am J Clin Pathol. 2004;122(1):110-9.

26. Kallioniemi OP, Kallioniemi A, Kurisu W, Thor A, Chen LC, Smith HS, Waldman FM, Pinkel D, Gray JW. ERBB2 amplification in breast cancer analyzed by fluorescence in situ hybridization. Proc Natl Acad Sci U S A. 1992;89(12):5321-5.

27. Mass RD, Press MF, Anderson S, Cobleigh MA, Vogel CL, Dybdal N, Leiberman G, Slamon DJ. Evaluation of clinical outcomes according to HER2 detection by fluorescence in situ hybridization in women with metastatic breast cancer treated with trastuzumab. Clin Breast Cancer. 2005;6(3):240-6.

28. Pauletti G, Godolphin W, Press MF, Slamon DJ. Detection and quantitation of HER-2/neu gene amplification in human breast cancer archival material using fluorescence in situ hybridization. Oncogene. 1996;13(1):63-72.

29. Persons DL, Borelli KA, Hsu PH. Quantitation of HER-2/neu and c-myc gene amplification in breast carcinoma using fluorescence in situ hybridization. Mod Pathol. 1997;10(7):720-7. 
30. Press MF, Bernstein L, Thomas PA, Meisner LF, Zhou JY, Ma Y, Hung G, Robinson RA, Harris C, El-Naggar A. HER-2/neu gene amplification characterized by fluorescence in situ hybridization: poor prognosis in nodenegative breast carcinomas. J Clin Oncol. 1997;15(8):2894-904.

31. Portier BP, Wang Z, Downs-Kelly E, Rowe JJ, Patil D, Lanigan C, Budd GT, Hicks DG, Rimm DL, Tubbs RR. Delay to formalin fixation 'cold ischemia time': effect on ERBB2 detection by in-situ hybridization and immunohistochemistry. Mod Pathol. 2013;26(1):1-9.

32. Ross JS, Fletcher JA, Bloom KJ, Linette GP, Stec J, Clark E, Ayers M, Symmans WF, Pusztai L, Hortobagyi GN. HER-2/neu testing in breast cancer. Am J Clin Pathol. 2003;120(Suppl):S53-71.

33. Dybdal N, Leiberman G, Anderson S, McCune B, Bajamonde A, Cohen RL, Mass RD, Sanders C, Press MF. Determination of HER2 gene amplification by fluorescence in situ hybridization and concordance with the clinical trials immunohistochemical assay in women with metastatic breast cancer evaluated for treatment with trastuzumab. Breast Cancer Res Treat. 2005; 93(1):3-11.

34. Perez EA, Press MF, Dueck AC, Jenkins RB, Kim C, Chen B, Villalobos I, Paik S, Buyse $M$, Wiktor AE. Immunohistochemistry and fluorescence in situ hybridization assessment of HER2 in clinical trials of adjuvant therapy for breast cancer (NCCTG N9831, BCIRG 006, and BCIRG 005). Breast Cancer Res Treat. 2013;138(1):99-108.

35. Press MF, Slamon DJ, Flom KJ, Park J, Zhou JY, Bernstein L. Evaluation of HER-2/neu gene amplification and overexpression: comparison of frequently used assay methods in a molecularly characterized cohort of breast cancer specimens. J Clin Oncol. 2002;20(14):3095-105.

36. Sorscher SM. HER-2 overexpression in breast tumors lacking gene amplification. J Clin Oncol. 2004;22(20):4232. author reply 4232-4233.

37. Vanden Bempt I, Van Loo P, Drijkoningen M, Neven P, Smeets A, Christiaens MR, Paridaens R, Wolf-Peeters C. Polysomy 17 in breast cancer: clinicopathologic significance and impact on HER-2 testing. J Clin Oncol. 2008;26(30):4869-74

38. Lehmann-Che J, Amira-Bouhidel F, Turpin E, Antoine M, Soliman H, Legres L, Bocquet C, Bernoud R, Flandre E, Varna M. Immunohistochemical and molecular analyses of HER2 status in breast cancers are highly concordant and complementary approaches. Br J Cancer. 2011;104(11):1739-46.

39. Baehner FL, Achacoso N, Maddala T, Shak S, Quesenberry Jr CP, Goldstein LC, Gown AM, Habel LA. Human epidermal growth factor receptor 2 assessment in a case-control study: comparison of fluorescence in situ hybridization and quantitative reverse transcription polymerase chain reaction performed by central laboratories. J Clin Oncol. 2010;28(28):4300-6.

40. Cuadros M, Talavera P, Lopez FJ, Garcia-Perez I, Blanco A, Concha A. Realtime RT-PCR analysis for evaluating the Her2/neu status in breast cancer. Pathobiology. 2010;77(1):38-45

41. Dabbs DJ, Klein ME, Mohsin SK, Tubbs RR, Shuai Y, Bhargava R. High falsenegative rate of HER2 quantitative reverse transcription polymerase chain reaction of the Oncotype DX test: an independent quality assurance study. J Clin Oncol. 2011;29(32):4279-85

42. Nistor A, Watson PH, Pettigrew N, Tabiti K, Dawson A, Myal Y. Real-time PCR complements immunohistochemistry in the determination of HER-2/neu status in breast cancer. BMC Clin Pathol. 2006:6:2

43. Noske A, Loibl S, Darb-Esfahani S, Roller M, Kronenwett R, Muller BM, Steffen J, Toerne C, Wirtz R, Baumann I. Comparison of different approaches for assessment of HER2 expression on protein and mRNA level: prediction of chemotherapy response in the neoadjuvant GeparTrio trial (NCT00544765). Breast Cancer Res Treat. 2011:126(1):109-17.

44. Park S, Wang HY, Kim S, Ahn S, Lee D, Cho Y, Park KH, Jung D, Kim SI, Lee $H$. Quantitative RT-PCR assay of HER2 mRNA expression in formalin-fixed and paraffin-embedded breast cancer tissues. Int J Clin Exp Pathol. 2014; 7(10):6752-9.

45. Bartlett JM, Starczynski J. Quantitative reverse transcriptase polymerase chain reaction and the Oncotype DX test for assessment of human epidermal growth factor receptor 2 status: time to reflect again? J Clin Oncol. 2011;29(32):4219-21.

46. Schmittgen TD, Livak KJ. Analyzing real-time PCR data by the comparative C(T) method. Nat Protoc. 2008:3(6):1101-8.

47. Budczies J, Klauschen F, Sinn BV, Gyorffy B, Schmitt WD, Darb-Esfahani S, Denkert C. Cutoff Finder: a comprehensive and straightforward Web application enabling rapid biomarker cutoff optimization. PLoS One. 2012; 7(12):e51862.
48. Baselga J, Swain SM. Novel anticancer targets: revisiting ERBB2 and discovering ERBB3. Nat Rev Cancer. 2009;9(7):463-75.

49. Gonzalez de Castro D, Clarke PA, Al-Lazikani B, Workman P. Personalized cancer medicine: molecular diagnostics, predictive biomarkers, and drug resistance. Clin Pharmacol Ther. 2013;93(3):252-9.

50. Dienstmann R, Rodon J, Tabernero J. Biomarker-driven patient selection for early clinical trials. Curr Opin Oncol. 2013;25(3):305-12.

51. Patani N, Martin LA, Dowsett M. Biomarkers for the clinical management of breast cancer: international perspective. Int J Cancer. 2013;133(1):1-13.

52. Kulasingam $V$, Diamandis EP. Strategies for discovering novel cancer biomarkers through utilization of emerging technologies. Nat Clin Pract Oncol. 2008;5(10):588-99.

53. Pasic MD, Samaan S, Yousef GM. Genomic medicine: new frontiers and new challenges. Clin Chem. 2013;59(1):158-67.

54. Pasic MD, Yousef GM, Diamandis EP. The proteomic revolution in laboratory medicine. Clin Biochem. 2013;46(6):397-8.

55. Altman RB. Personal genomic measurements: the opportunity for information integration. Clin Pharmacol Ther. 2013;93(1):21-3.

56. Bartlett G, Zgheib N, Manamperi A, Wang W, Hizel C, Kahveci R, Yazan Y. Pharmacogenomics in primary care: a crucial entry point for global personalized medicine? Curr Pharmacogenomics Person Med. 2012;10(2):101-5.

57. Dienstmann R, Rodon J, Barretina J, Tabernero J. Genomic medicine frontier in human solid tumors: prospects and challenges. J Clin Oncol. 2013;31(15): 1874-84.

58. Lewis S, Locker A, Todd JH, Bell JA, Nicholson R, Elston CW, Blamey RW, Ellis 1O. Expression of epidermal growth factor receptor in breast carcinoma. J Clin Pathol. 1990;43(5):385-9.

59. Siegel PM, Ryan ED, Cardiff RD, Muller WJ. Elevated expression of activated forms of Neu/ErbB-2 and ErbB-3 are involved in the induction of mammary tumors in transgenic mice: implications for human breast cancer. EMBO J. 1999;18(8):2149-64.

60. Travis A, Pinder SE, Robertson JF, Bell JA, Wencyk P, Gullick WJ, Nicholson RI, Poller DN, Blamey RW, Elston CW. C-erbB-3 in human breast carcinoma: expression and relation to prognosis and established prognostic indicators. Br J Cancer. 1996;74(2):229-33.

61. Tucker T, Marra M, Friedman JM. Massively parallel sequencing: the next big thing in genetic medicine. Am J Hum Genet. 2009:85:142-54.

62. Gingras I, Sonnenblick A, De Azambuja E, Paesmans M, Delaloge S, Aftimos $P$, Piccart MJ, Sotiriou C, Ignatiadis M, Azim HA. The current use and attitudes towards tumor genome sequencing in breast cancer. Sci Rep. 2016:6:22517

63. Roychowdhury S, Chinnaiyan AM. Translating cancer genomes and transcriptomes for precision oncology. CA Cancer J Clin. 2016;66:75-88.

64. Costa V, Angelini C, De Feis I, Ciccodicola A. Uncovering the complexity of transcriptomes with RNA-Seq. J Biomed Biotechnol. 2010;2010:853916.

65. Wang Y, Yang Q, Wang Z. The evolution of nanopore sequencing. Front Genet. 2015;5:449.

66. Metzker ML. Sequencing technologies-the next generation. Nat Rev Genet. 2010;11(1):31-46.

67. Fend F, Raffeld M. Laser capture microdissection in pathology. J Clin Pathol. 2000;53:666-72

\section{Submit your next manuscript to BioMed Central and we will help you at every step:}

- We accept pre-submission inquiries

- Our selector tool helps you to find the most relevant journal

- We provide round the clock customer support

- Convenient online submission

- Thorough peer review

- Inclusion in PubMed and all major indexing services

- Maximum visibility for your research

Submit your manuscript at www.biomedcentral.com/submit 